Key words: angular contact ball bearings, selection of preload, basic rating life, moment of friction of bearing, durability of bearing

\title{
THE INFLUENCE OF PRELOAD ON THE WORK OF ANGULAR CONTACT BALL BEARINGS
}

\begin{abstract}
Optimum values of preload can be achieved in well-tried constructions and then applied in similar structures. For new structures, it is recommended to calculate the preload force and to test the correctness of calculation by means of experiments. In practice it may be necessary to introduce corrections, because not all real work parameters can be precisely known. Credibility of calculations depends, first of all, on the consistence between the assumptions concerning temperature conditions during work and elastic deformations of cooperating elements - first of all of a holder - and the real work conditions. The aim of the study is to determine how preload influences the work of a system of angular ball bearings, in relation to durability of bearing, moment of friction and rigidity of the bearing.
\end{abstract}

\section{Introduction}

According to literature [1-4] the main reason for applying a preload are the following beneficial effects:

- increasing stiffness of a system of bearings,

- reduction of noise during work,

- increase of accuracy of shaft guidance,

- compensation of wearing off and subsidence processes during work,

- assurance of longer exploitation time.

Stiffness of bearing (often in $\mathrm{kN} / \mu \mathrm{m}$ ) is defined as a relation of a force acting on the bearing to elastic deformation of the bearing. The deformation of the bearing caused by the load in preloaded bearings is lower within the given

\footnotetext{
${ }^{1}$ Institute of Environmental Engineering and Building Installations, Technical University of Lodz, Al. Politechniki 6, 90-924 Lodz, Poland. Emails: jaroslaw.kaczor@p.lodz.pl, andrzej.raczynski@p.lodz.pl
} 
range of loads than in the bearings without preload and depends on the applied preload and the load value.

The larger the operating clearance in the bearing, the poorer the guidance of rolling elements in the non-loaded area, the more intense the vibrations of the bearing system and the louder the work of the bearings. Reduction of clearance and choosing a preload results in reduction of noise [5]. Yet the above takes place only up to a certain value of preload. Excessive load results in an increase of contact loads between rolling parts and rings in the bearing, which leads to a "harder" work of the bearing, causing increased noise. Thus, there exists certain optimum of preload due to the noisiness of the bearing.

It must be remembered that not only the preload affects the noise, but also a quality of bearing races, their degree of wear and the load value. Preloaded bearings assure more accurate shaft guidance, because preload reduces the shaft tendency to bend under the influence of load. In some applications, the systems of preloaded bearings can demonstrate higher reliability of work and longer life-span. A correctly determined preload can have a positive influence on the distribution of loading of rolling parts in the bearings and thus on their durability [6]. For example, higher accuracy of guidance and higher stiffness assured by preloaded bearings of a pinion and bearings of a differential mechanism means that the co-face of the teeth will be more accurate, the value of contact will be more stable, and dynamic forces will be minimized [3]. As a result, the work will be less noisy, and the teeth in the bearing will be in a good condition for a longer time. The wearing-off and subsidence processes in a system of bearings during work result in the tendency to clearance formation. Yet, the above can be compensated by the increase in preload as time progresses.

The aim of the study is to determine how the preload influences the work of a system of angular ball bearings, in relation to durability of bearing, moment of friction and rigidity of the bearing.

\section{Calculation method}

In the study, it was necessary to associate the following issues:

1. the line of shaft deflection for complex external load,

2. the displacements of inner bearing rings in relation to the outer ones resulting from loads and preload,

3. the influence of thermal deformations of the shaft and its fitting on the displacements,

4. the deformations in the contact between the rolling parts and the race of both bearings in the system,

5. the contact strengths in bearings calculated on the basis of contact deformations, 
6. the balance between internal (contact) forces in the bearings and the load of the whole bearing,

7. durability of the bearings calculated on the basis of contact forces.

A selection of a calculation method is a critical step on the way to theoretically solving the problem. The assumed model determines the degree to which the reality is approached, the extent of the included phenomena, as well as the workload needed to apply a given solution. In the applications referring to the phenomena taking place in roller bearings, the calculation models are usually not revealed in detail. The study presents a description of a modelling method elaborated by the authors and applied in the studies $[5,7,8]$ and other. The following simplifying assumptions have been made:

1. The bearing material is an isotropic and it is a subject to Hooke's law;

2. The working surfaces of bearings are perfectly smooth;

3. There occur no errors in the shape of balls or the bearing rings or shaft;

4. Bearings are embedded in the fittings with no geometrical errors, and the clearances associated with pressing of the bearings are neglected, which means that the axes of outer rings in the bearings are always located along one straight line;

5. The analysis of the ball loads does not account for mass forces, basket impacts or resistance of a lubricant;

6. Contact tangential forces have no significant influence on elastic strains and they are ignored;

7. In calculations of pressure distributions, the contact of a ball with toroidal race is modelled theoretically as a point-contact, which then transforms into an elliptical contact (a subject to Hertz theory) under a load;

8. Distribution of loads in the contact point of rolling elements and races is the same in motion and with static load;

9. Elastic strains in elements of bearings occur only in the areas of contact between the balls and the rings, thanks to which non-operating surfaces of the rings maintain their cylindrical or flat shape.

\subsection{Longitudinal stiffness of bearing}

Longitudinal (axial) stiffness of a bearing is determined by the relations of the total external axial force operating on the bearing $\sum F_{x}$ to elastic displacement of the shaft. Within the developed calculation procedure, the elastic shaft deflection is not determined, yet the values of axial displacements of the inner rings (i.e. axial elastic deflexion) in relation to the outer ones are calculated for each bearing. They are marked $f_{A x}$ and $f_{B x}$. The knowledge of both the displacements makes it possible to determine the shaft displacement. Fig. 1 
symbolically presents a shaft with inner rings of the bearings (thick, horizontal line) and the outer rings of both bearings (vertical lines).

1)

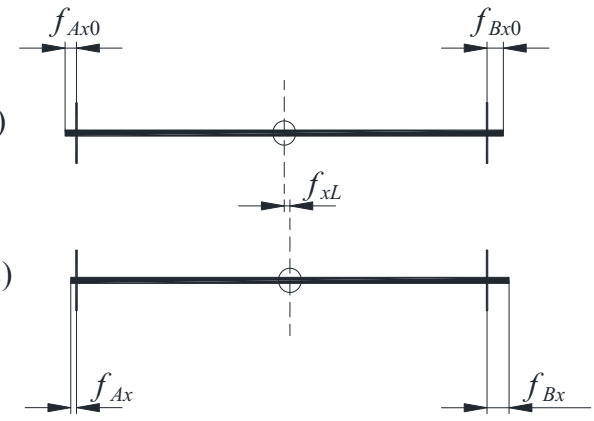

Fig. 1. Illustration for determining an axial displacement of a shaft

The state marked as 1 is a situation in which the external axial force does not operate. In this situation, internal axial displacements in the bearings $f_{A x 0}$ and $f_{B x 0}$ result from the values of radial forces (radial reactions of bearings). If the bearings are identical and their radial reactions are identical, with the external axial force equal " 0 ", the axial displacements in both bearings are identical and equal half of the preload value. Yet, it is a rare case, so axial displacements differ. Still, irrespective if they are equal or different, a preliminary location of a selected point on the shaft (e.g. of its central point) with " 0 " external axial force, can be determined according to the relation:

$$
x_{L 0}=0.5\left(f_{B x 0}-f_{A x 0}\right) .
$$

When an axial force oriented (for example) to the right appears and causes the shaft displacement (situation 2), the internal axial displacement in the right bearing $f_{B x}$ increases and the internal axial displacement in the left bearing $f_{A x}$ decreases, compared to those appearing in the situation (1). Thus, a new location of a selected point on the shaft can be determined:

$$
x_{L F}=0.5\left(f_{B x}-f_{A x}\right) .
$$

The change of location of a selected point on the shaft is the shaft displacement. Hence, this displacement is expressed by the relation:

$$
f_{x L}=x_{L F}-x_{L 0} .
$$

Thanks to the fact that the shaft displacement and the sum of external axial forces $\sum F_{x}$ are known, the longitudinal stiffness of the bearing can be determined:

$$
C_{x}=\frac{\sum F_{x}}{f_{x L}} .
$$


The presented procedure of determining a longitudinal stiffness of the bearing requires the knowledge of shaft location for zero axial force, based on which one can make the necessary calculations for a number of values of axial forces, the first of which must equal zero (in the initial calculation $\sum F_{x}=0$ ).

\subsection{Frictional moment of bearing}

A friction causing the resistance of movement is an inevitable phenomenon accompanying the movement of each mechanism. The above applies also to roller bearings. A frictional moment, also known as the moment of movement resistance, is a parameter characterizing the size of the phenomenon. In development of mechanisms, one aims at minimisation of movement resistances. A strong resistance of movement means, at least, an increased use of energy for maintaining the mechanism in motion, with all the consequences for energy economy and for the natural environment. Another consequence of the increase of the frictional moment is increased heat generation, which can result in a drop of resistance of elements or degradation of lubricating agents, which often leads to a breakdown. In some cases (e.g. in measuring equipment of rotational movement) the increase of movement frictions affects the accuracy of readings by this equipment.

A frictional moment in the bearing consists of frictional moments in both bearings and in the sealings located either outside of the bearings or within them. The moment of friction appearing in the bearings also consists of two parts: the mechanical friction in the contact between the rolling parts with the races and hydraulic resistances, caused by displacement of the lubricating agent. In the aspect of this study, only mechanical resistances of rolling parts movements are important because only they depend on the preload in the bearings. According to the ball-bearings catalogues [9], the moment of mechanical friction $M_{1}$ is defined by the formula:

$$
M_{1}=\mu_{1} f_{1} P_{0} \frac{d_{m}}{2}
$$

where:

$P_{0}$ - the equivalent resting load of a bearing,

$f_{1}$ - the ratio depending on the type of bearing; for angular ball-bearings, series B it equals 1 ,

$d_{m}$ - pitch diameter of the bearing,

$\mu_{1}-$ the ratio of friction, for angular roller-bearings in series B it is defined by the formula:

$$
\mu_{1}=0.0015\left(\frac{P_{0}}{C_{0}}\right)^{\frac{1}{3}} .
$$


The equivalent load $P_{0}$ depends on the radial force $F_{r}$ as well as the axial load $F_{a}$ of the bearing. Yet, the above is expressed with the use of the formula:

$$
P_{0}=0.5 F_{r}+0.26 F_{a}, \quad \text { where must be } P_{0} \geq F_{r} \text {. }
$$

Thus, the above method is an approximate one. Hence, it is noticeable that the formula recommended by the catalogues is not a precise one: it loosely takes into account the axial load, provides no grounds for considering preload, moreover, neglects the phenomenon of the increase of load of rolling parts as a result of shaft deflection.

Therefore, the following course of action is proposed in this study:

The starting point is that, in accordance with formula (5), the friction moment of a specific angular contact ball bearing in B series (having a given diameter $d_{m}$ ) is proportional to the product of friction ratio $\mu_{1}$ and the equivalent load $P_{0}$. According to formula (6), the friction ratio of a specific bearing (with a given static load $C_{0}$ ) is proportional to the cube root of the equivalent load: $\mu_{1} \approx P_{0}^{\frac{1}{3}}$. Then, the friction moment of a specific bearing can be expressed by the following relationship:

$$
\begin{gathered}
M_{1} \approx P_{0} P_{0}^{\frac{1}{3}}, \\
M_{1} \approx P_{0}^{\frac{4}{3}} .
\end{gathered}
$$

The equivalent load of a bearing is proportional to the sum of the load of all balls in the bearing. Thus, one can say that the moment of mechanical friction $M_{1}$ is proportional to the sum of loads of all balls in the bearing, raised to the power $4 / 3$ :

$$
M_{1} \approx\left(\sum Q\right)^{\frac{4}{3}} .
$$

The moment of mechanical friction of the whole bearing system consisting of two bearings (bearing A and B) is the sum of friction moments of both bearings:

$$
M=M_{1 A}+M_{1 B} \approx\left(\sum Q_{A}\right)^{\frac{4}{3}}+\left(\sum Q_{B}\right)^{\frac{4}{3}} .
$$

It is fully sufficient to determine the right side of expression (8) to meet the objectives formulated in the study concerning the influence that the preload exerts on the parameters of work of the bearing. Thanks to calculating the value of the expression $\left(\sum Q_{A}\right)^{\frac{4}{3}}+\left(\sum Q_{B}\right)^{\frac{4}{3}}$ it is possible to find a relative (percentage-based) change in the moment of friction depending on the applied preload. 


\subsection{Fatigue life of a bearing}

The study [1] proves that, basing on the statistical approach of Weibull theory, one can obtain the following form of the expression determining fatigue life of a roller bearing:

$$
L=\left(\frac{C}{P}\right)^{p}
$$

$L$ means the number of the millions of rotations that will be most probably performed by the bearing before significant damage of the race or of rolling parts occurs. The exponent $p$ is a number taking different values for different types of bearings. For roller bearings, the exponent $p=3$ is commonly assumed.

Thus, in the calculations presented in this part of the study, the following form of the formula is used:

$$
L=\left(\frac{C}{P}\right)^{3} .
$$

The dynamic load rating $\mathrm{C}$ is adopted from the catalogue of a roller bearings producer.

For final calculations of durability of bearings one takes a substitute load. It is calculated basing on deformations occurring in the bearing, taking into consideration all displacements and tilts in the system of bearings.

At the same time (for comparison), it was made possible to calculate the so-called catalogue durability, i.e. the durability determined basing on the catalogue equivalent load:

$$
L=\left(\frac{C}{P_{c}}\right)^{3} .
$$

The catalogue equivalent load is calculated according to the classical formula:

$$
P_{c}=X F_{r}+Y F_{a} .
$$

By applying the symbols assumed in this study, one obtains the following form of formula:

$$
P_{c}=X P_{r 0}+Y P_{x 0}
$$

where the radial reaction of $R_{r 0}$ bearing results from geometrical summing of reactions acting in directions $y$ and $z$ :

$$
R_{r 0}=\sqrt{\left(R_{y 0}\right)^{2}+\left(R_{z 0}\right)^{2}} .
$$


Determining the transversal reactions of supports $\left(R_{A y 0}, R_{A z 0}, R_{B y 0}\right.$ and $R_{B z 0}$ ) is carried out according to the rules of statics. In accordance with the earlier assumptions, nodal points of bearings reaction are regarded as the shaft points of support. In the first approach (the first stage of computer procedure), only the forces operating on the presumed gear wheels are taken into consideration. These forces are transformed to the axis $x-y-z$ as $F_{x}, F_{y}$, $F_{z}$. At farther stages of the calculation procedure we include into calculations, besides these concentrated forces, also the reaction moments $M_{x z}$ and $M_{x y}$, generated in the bearings $\mathrm{A}$ and $\mathrm{B}$ as the response to shaft deflection. The complete calculation scheme for transverse reactions of supports in both planes is presented in Fig. 2.
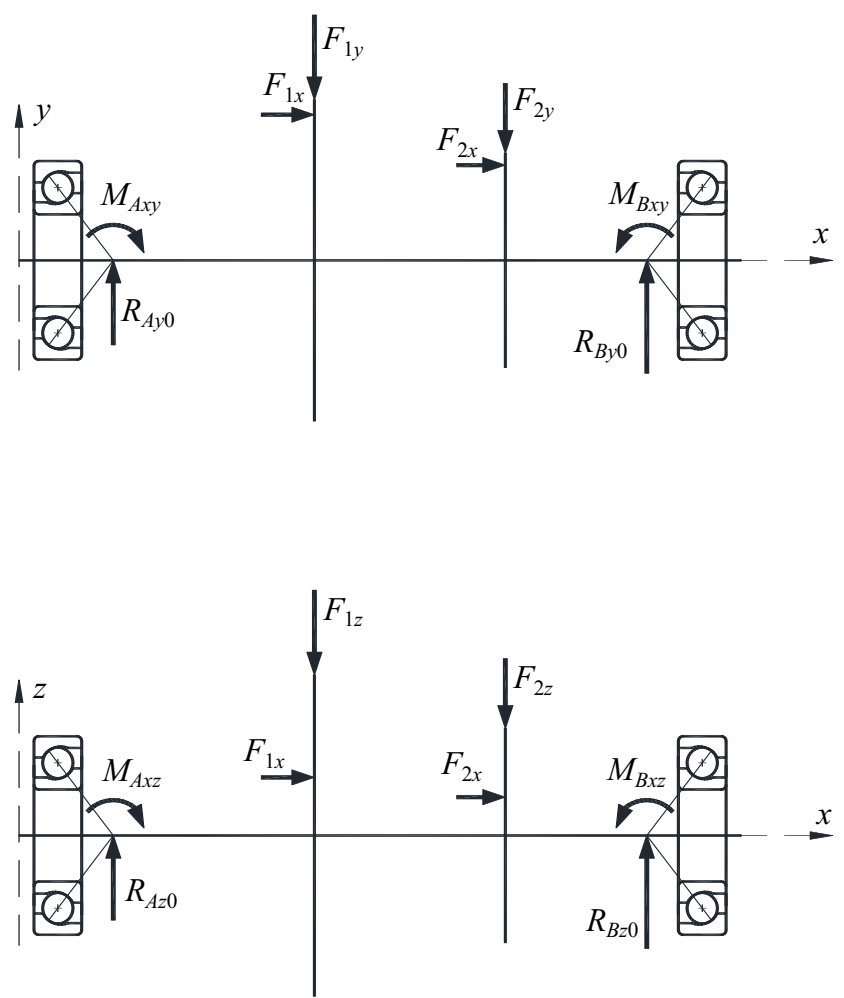

Fig. 2. Calculation scheme for transverse reactions of supports

For the purpose of calculating transverse reactions in each of the presented planes $(x-y$ and $x-z)$ one uses the equations of moments and equations of the sum of projections of forces on the axis perpendicular to the axis of the shaft. This is a routine procedure that demands no description.

Axial reactions of supports also must satisfy the equation of the balance of forces projected onto the axis $x$. In this equation, there appear internal forces 
in the bearings and all external axial forces. The following condition has to be fulfilled:

$$
R_{A x}+\sum F_{i x}-R_{B x}=0 .
$$

Illustration - in Fig. 3.

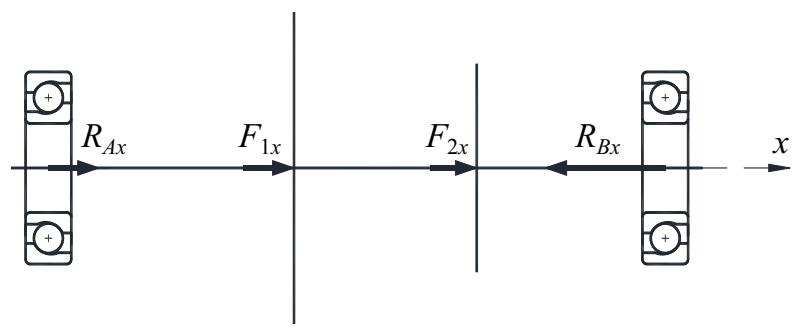

Fig. 3. Calculation scheme for axial reactions of supports

The durability determined on the basis of substitute load calculated in formula (11) does not depend on preload and on shaft deflection, because it is based on a very simplified (static) approach to loads in bearings. Thus, it will be treated only as a comparison dimension. Fatigue life of both bearings in the bearing system (marked A and B) determined on the basis of the formula (10) is a criterion for comparing the consequences of various values of preload for various types of bearings. As it may happen there as a result of applying the preload, the durability of one bearing improves whereas that of the other one decreases. For this reason, another indicator, called the durability of bearing indicator $W_{T}$, has been introduced. The indicator will be determined according to formula [7]:

$$
W_{T}=\frac{L_{A}}{L_{A 0}} \frac{L_{B}}{L_{B 0}} .
$$

where:

$L_{A}, L_{B}$ - durability of A and B bearings calculated for a specific set of load data and the applied preload,

$L_{A 0}, L_{B 0}$ - durability of A and B bearings calculated with a specific set of load data and zero preload.

The indicator will be used in a graphic presentation of calculation results.

\section{Analytical calculations}

Angular contact ball bearings work only in systems and have to be considered in such systems, especially if the force of preload has to be taken into consideration. The forces appearing in bearings, and accordingly the durability of bearings, depend on numerous factors, such as: the size and the series of bearings, load per each bearing in the system and shaft deflection. The load 
per bearing depends, among other things, on e.g. type, size and number of gear wheels installed on the shaft, the location of cooperating wheel, shape of the shaft defined by its total length and by the diameters varied at length. There exist an infinite number of possible cases, therefore a specific construction was assumed here.

The authors selected a convergent system of two angular contact ball bearings 7212B with the following dimensions of working areas: the diameter of the balls $D_{k}=15.875 \mathrm{~mm}$, the diameter of the inner ring raceway $d_{b w}=$ $=68.976 \mathrm{~mm}$, the diameter of the outer ring raceway $d_{b z}=101.059 \mathrm{~mm}$, the transverse radius of the inner ring raceway $r_{b w}=8.180 \mathrm{~mm}$, the transverse radius of the outer ring raceway $r_{b z}=8.330 \mathrm{~mm}$, the number of balls $Z=15$ and the dynamic load capacity of $C=57200 \mathrm{~N}$ [10]. A model shaft has been established, with the shape presented in Fig. 4. The bearings are located on the ends of the shaft (the bearing on the left side is marked „A", and the one on the right side - „B”), while the diameters on particular sections comply with the theoretical outline built according to the rule approximately equalling the flexural strength.

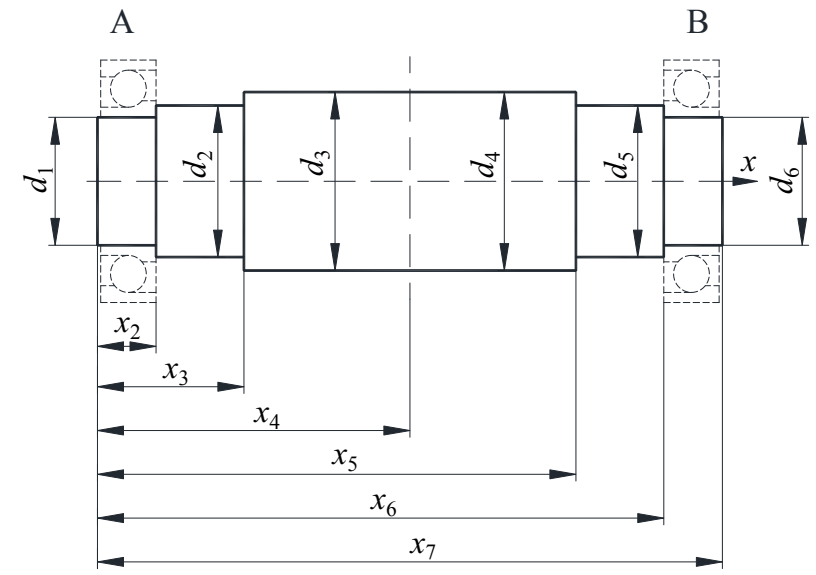

Fig. 4. Draft of a model shaft

Dimensions of a model shaft are presented in Table 1.

The adopted model of a shaft was the subject to calculations for loads presented in Fig. 5. It is assumed that the load is applied on two sides of one gear wheel, located at a distance $x_{L}$ from the beginning of the shaft. The circumferential forces $F_{c}$ are oriented in accordance with the axis $y$, the radial forces $F_{p}$ are oriented in accordance with the axis $z$, and the axial forces $F_{x}$ in accordance with the axis $x$. The locations of both planes have been assumed in predetermined relations to the length of shaft $L_{w}$, equal to the dimension $x_{7}$, and they are respectively: $x_{L}=0.4 L_{w}, x_{L}=0.5 L_{w}, x_{L}=0.6 L_{w}$. 
Dimensional parameters of model shafts [mm]

Table 1.

\begin{tabular}{|c|c||c|c|}
\hline Bearing $\rightarrow$ & $7212 \mathrm{~B}$ & Bearing $\rightarrow$ & $7212 \mathrm{~B}$ \\
\hline$x_{2}$ & 22 & $d_{1}$ & 60 \\
$x_{3}$ & 100 & $d_{2}$ & 67 \\
$x_{4}$ & 200 & $d_{3}$ & 75 \\
$x_{5}$ & 300 & $d_{4}$ & 75 \\
$x_{6}$ & 378 & $d_{5}$ & 67 \\
$x_{7}$ & 400 & $d_{6}$ & 60 \\
\hline
\end{tabular}

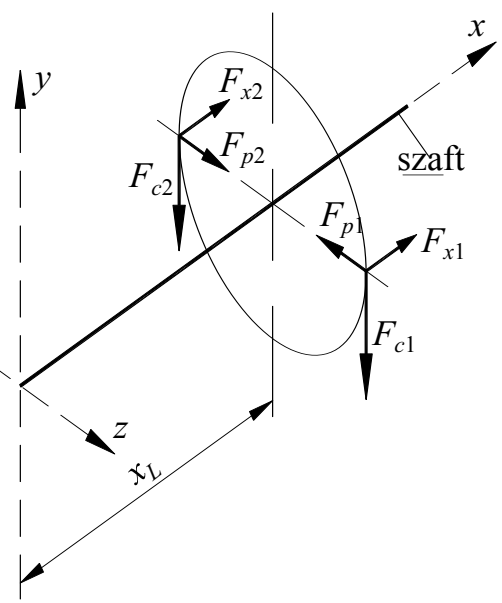

Fig. 5. Assumed variations of loads of the bearings

It has been assumed that the loads in loading points presented in Fig. 5 are the same, i.e. $F_{c 1}=F_{c 2}, F_{p 1}=F_{p 2}, F_{x 1}=F_{x 2}$. As a result, we obtained the balanced torques working on the shaft. The values of loads were assumed in specific relations with reference to the dynamic capacity of bearings $\mathrm{C}$. The circumferential force on the assumed gear wheel $F_{c 1}$ was established on the level of $0.1 C$. The radial force $F_{p}$ was established as approximately 0.364 of circumferential force with the assumption that the angle of preload of the mesh for the gear wheel is around $20^{\circ}$. It was assumed that the axial force $F_{x}$ takes five values: $0,0.049 F_{c}, 0.098 F_{c}, 0.196 F_{c}$, and $0.392 F_{c}$. These forces are determined in relation to the circumferential force.

Figs. 6 and 7 present separate characteristics of fatigue life for the left bearing (A) and the right bearing (B) depending on the preload $Z_{c}$, specified for the given variations of load.

As it can be noticed, in almost all cases, the characteristics of durability of bearing A and durability of bearing B have different courses: when one of them is up, the other one is down. It can be stated that the characteristics 


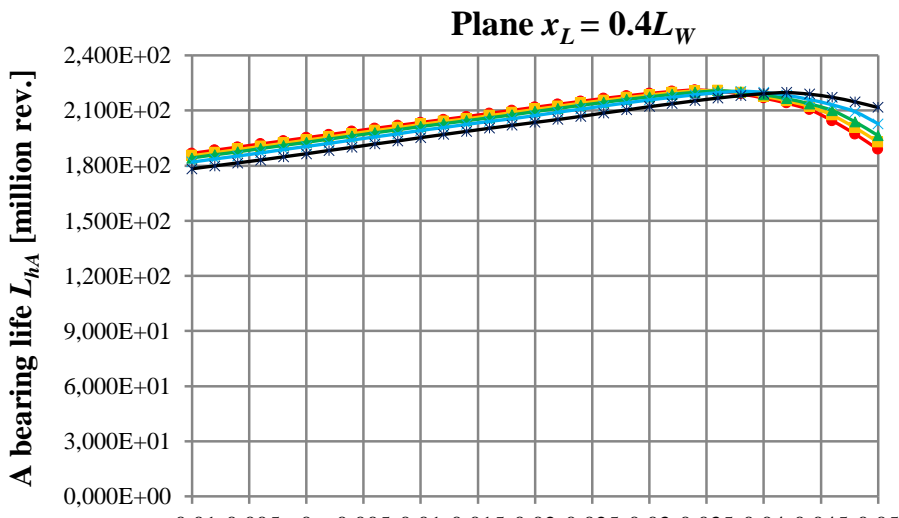

$$
F_{c 1}=0.1 C,
$$

$F_{p 1}=0.36 F_{c 1}$

$F_{c 2}=0.1 C$,

$F_{p 2}=0.36 F_{c 2}$

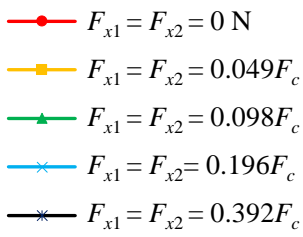

$\begin{array}{lllllllllllllllllll}-0,01-0,005 & 0 & 0,005 & 0,01 & 0,015 & 0,02 & 0,025 & 0,03 & 0,035 & 0,04 & 0,045 & 0,05\end{array}$

Preload $Z_{c}[\mathrm{~mm}]$

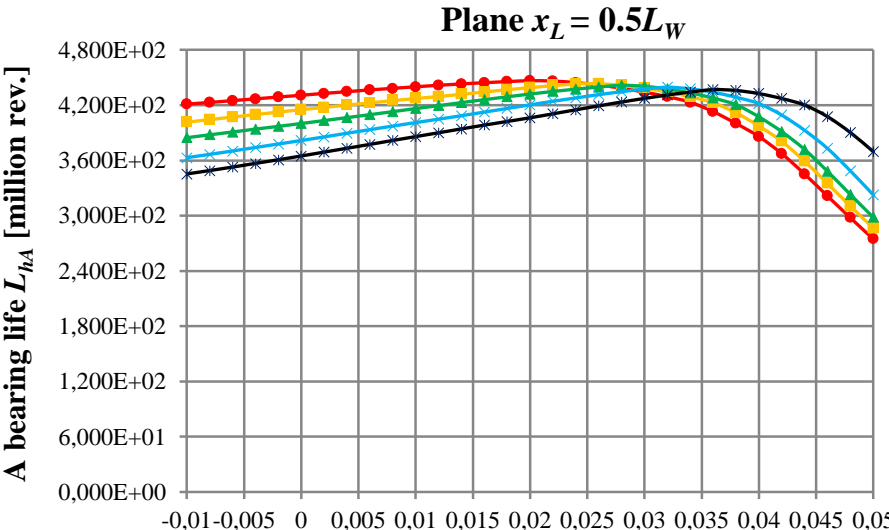

$F_{c 1}=0.1 C$,

$F_{p 1}=0.36 F_{c 1}$

$F_{c 2}=0.1 C$,

$F_{p 2}=0.36 F_{c 2}$

$\begin{aligned} \longrightarrow F_{x 1} & =F_{x 2}=0 \mathrm{~N} \\ \longrightarrow F_{x 1} & =F_{x 2}=0.049 F_{c} \\ \longrightarrow F_{x 1} & =F_{x 2}=0.098 F_{c} \\ \longrightarrow F_{x 1} & =F_{x 2}=0.196 F_{c} \\ \longrightarrow & F_{x 1}=F_{x 2}=0.392 F_{c}\end{aligned}$

$\begin{array}{llllllllllllllll}-0,01-0,005 & 0 & 0,005 & 0,01 & 0,015 & 0,02 & 0,025 & 0,03 & 0,035 & 0,04 & 0,045 & 0,05\end{array}$

Preload $Z_{c}[\mathrm{~mm}]$

Plane $x_{L}=0.6 L_{W}$

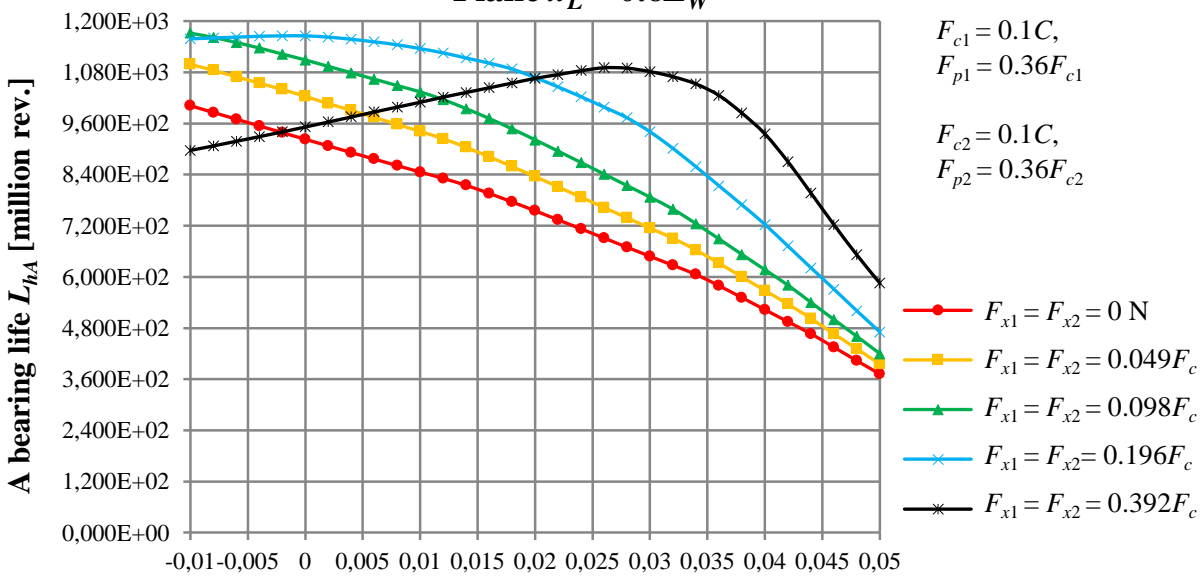

Preload $Z_{c}[\mathrm{~mm}]$

Fig. 6. Fatigue life of bearing A 


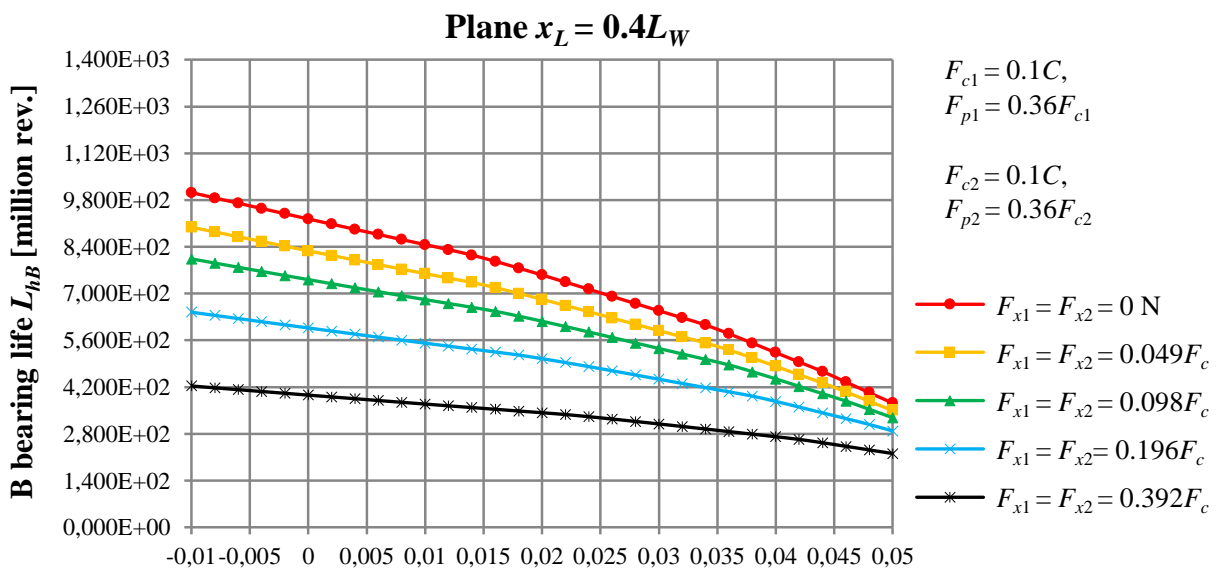

Preolad $Z_{c}[\mathrm{~mm}]$

Plane $x_{L}=0.5 L_{W}$

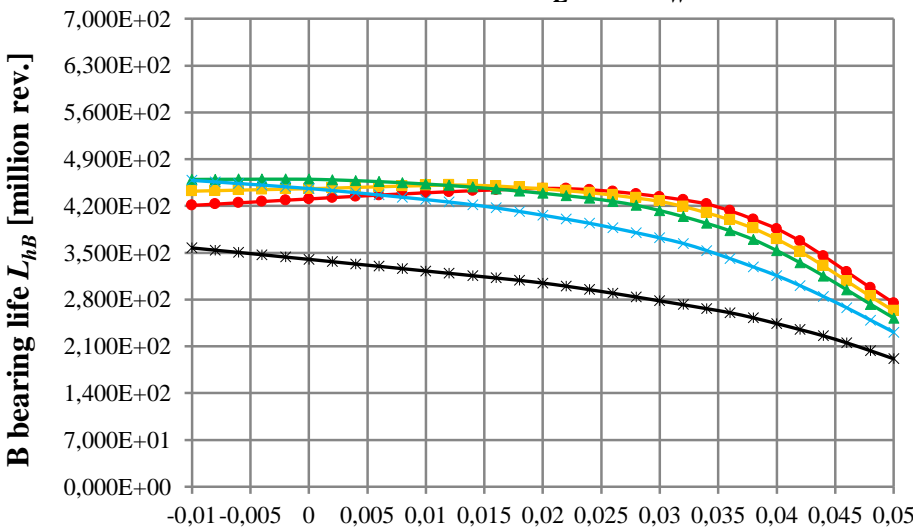

$F_{c 1}=0.1 C$,

$F_{p 1}=0.36 F_{c 1}$

$F_{c 2}=0.1 C$,

$F_{p 2}=0.36 F_{c 2}$

Preload $Z_{c}[\mathrm{~mm}]$

Plane $x_{L}=0.6 L_{W}$

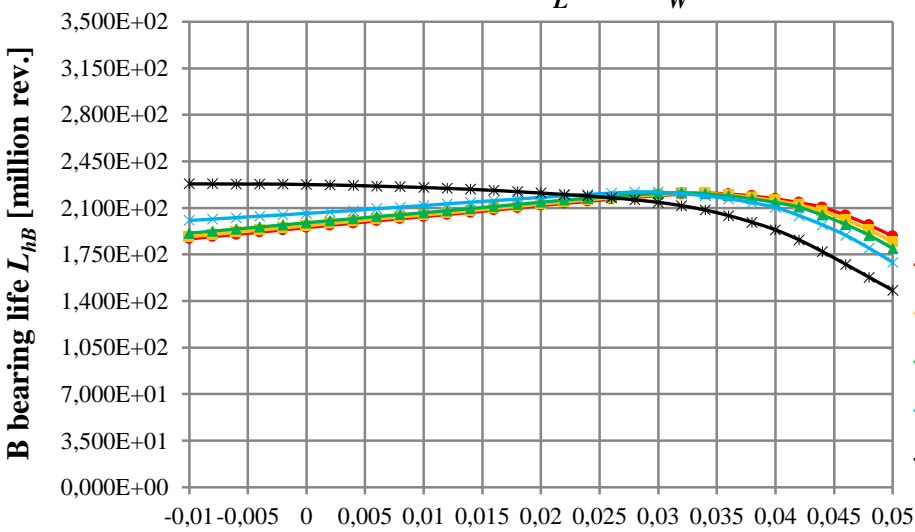

$F_{c 1}=0.1 C$,

$F_{p 1}=0.36 F_{c 1}$

$F_{c 2}=0.1 C$,

$F_{p 2}=0.36 F_{c 2}$

$\longrightarrow F_{x 1}=F_{x 2}=0 \mathrm{~N}$

- $F_{x 1}=F_{x 2}=0.049 F_{c}$

$\longrightarrow F_{x 1}=F_{x 2}=0.098 F_{c}$

$\smile F_{x 1}=F_{x 2}=0.196 F_{c}$

$F_{x 1}=F_{x 2}=0.392 F_{c}$

Preload $Z_{c}[\mathrm{~mm}]$

Fig. 7. Fatigue life of bearing B 
Plane $x_{L}=0.4 L_{W}$

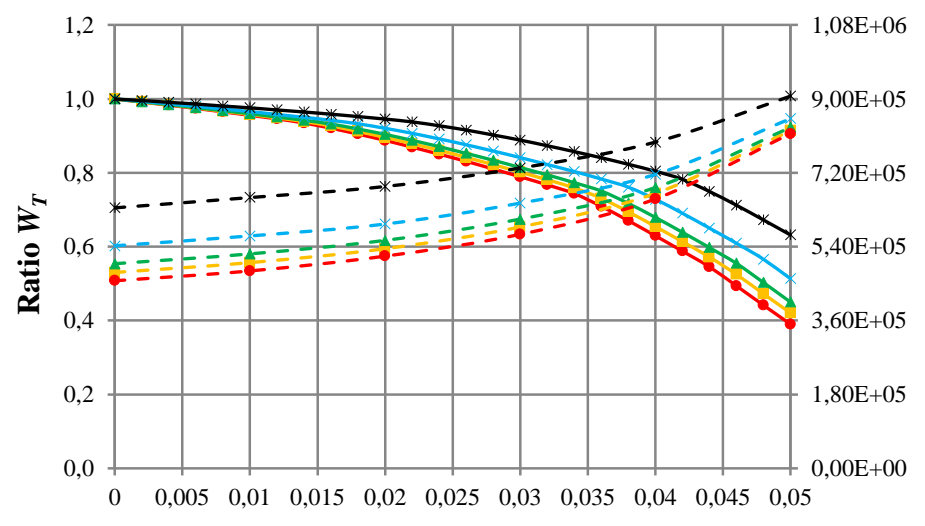

Preload $Z_{c}[\mathrm{~mm}]$

Plane $x_{L}=0.5 L_{W}$

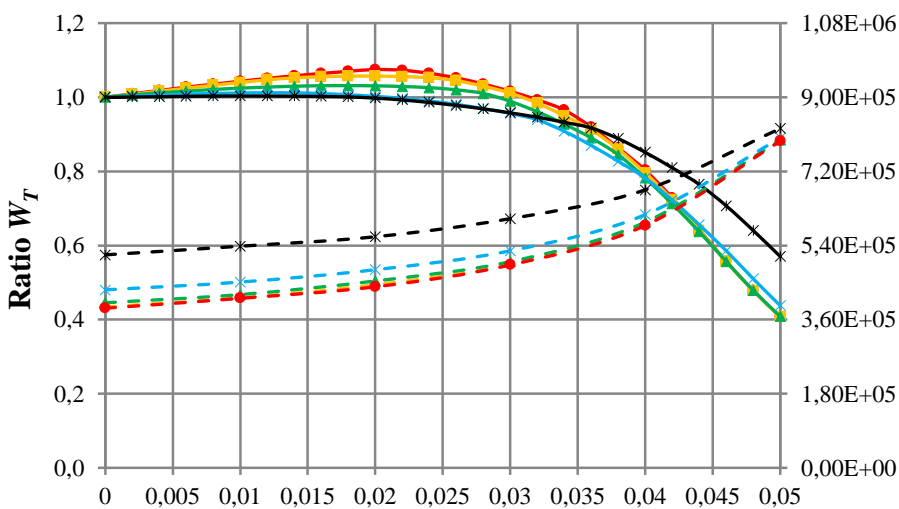

Preload $Z_{c}[\mathrm{~mm}]$

Plane $x_{L}=0.6 L_{W}$

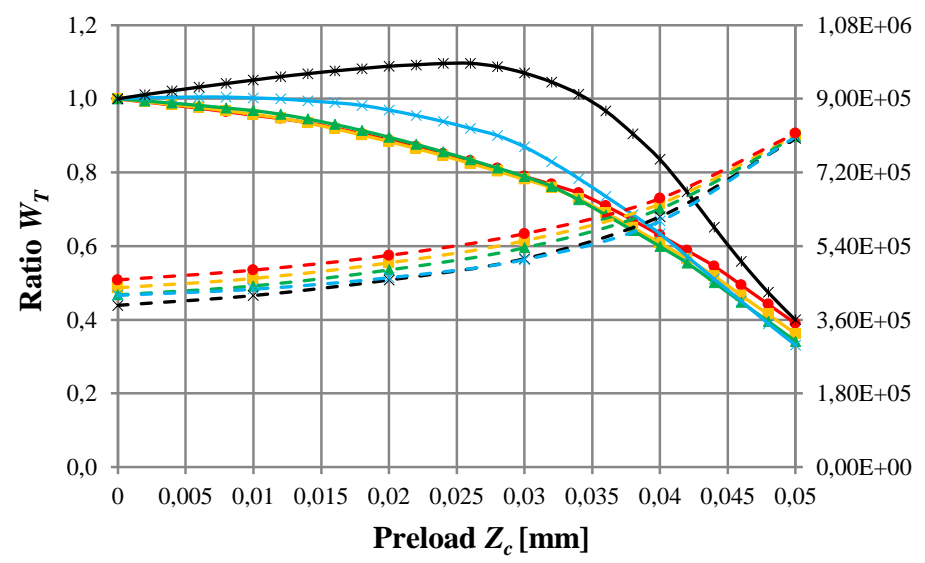

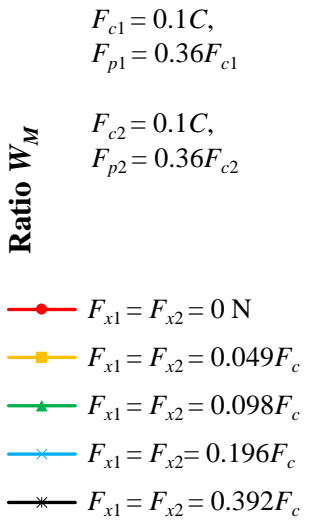

$F_{c 1}=0.1 C$,

$F_{p 1}=0.36 F_{c 1}$

$F_{c 2}=0.1 C$
$F_{p 2}=0.36 F_{c 2}$

刍

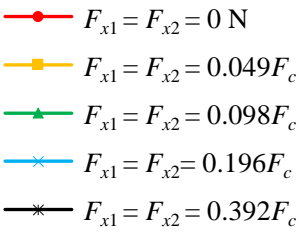

Fig. 8. Characteristics of indicator $W_{T}$ (continuous line) and $W_{M}$ (dotted line) for the given variation of load 

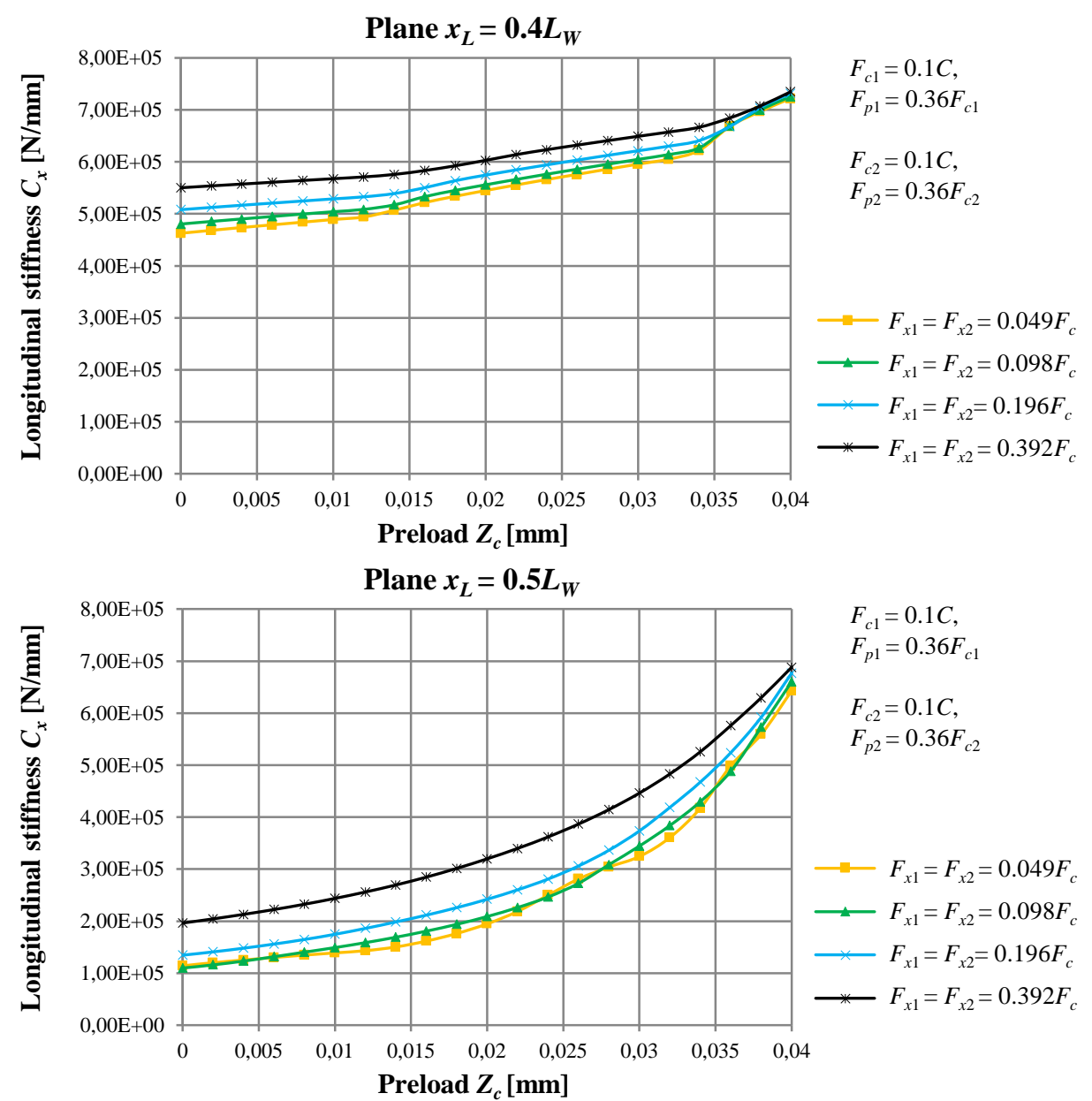

$$
\begin{aligned}
& F_{c 1}=0.1 C, \\
& F_{p 1}=0.36 F_{c 1} \\
& F_{c 2}=0.1 C, \\
& F_{p 2}=0.36 F_{c 2}
\end{aligned}
$$

Plane $x_{L}=0.6 L_{W}$

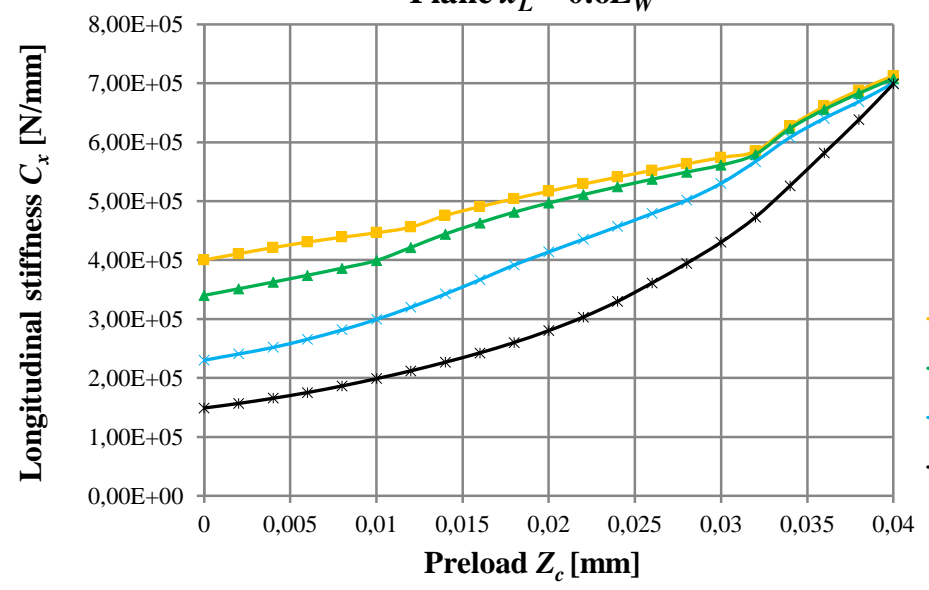

$F_{c 1}=0.1 C$

$F_{p 1}=0.36 F_{c 1}$

$F_{c 2}=0.1 C$

$F_{p 2}=0.36 F_{c 2}$

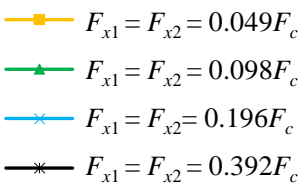

Fig. 9. Longitudinal stiffness $C_{x}$ for the assumed variation of load 
of bearings observed on a single basis will not provide any specific answer to the question what value of preload is optimal for the system of bearings. Accordingly, the characteristics of the indicator have been determined (basing on the formula (14)), connecting together durability properties of both bearings.

The formulation of $W_{T}$ indicator that includes both bearings allows one to compare durability of bearing systems. The characteristics of $W_{T}$ for the accepted example are presented in Fig. 8. Additionally, Fig. 8 presents characteristics of the indicator of the moment of friction $W_{M}$, which is proportional to the expression (8).

Fig. 9 presents longitudinal stiffness of the bearing, determined on the basis of expression (4).

\section{Conclusions}

The following observations result from the graphs:

As far as durability of bearings is concerned, one can notice that, if the loads are applied on the shaft closer to the left bearing, regardless of other factors (the size of longitudinal and axial loads), fatigue life of the left bearing (A) slowly rises to a certain value $Z_{c}$, and then rapidly drops as the preload $Z_{c}$ increases. A maximum is reached for various values $Z_{c}$ depending on the value of loads and on the size of the bearing. Still the first relation is weak, and the other one much stronger. However, the durability of the right bearing (B) in these conditions exhibits a significant drop in the whole considered range of the increase of preload, regardless of other parameters. Moreover, the curves of durability of bearing B lie on different levels depending on the axial load, which is understandable, as the axial load is oriented towards the right bearing.

If the loads are applied in the middle of the distance between the bearings, characteristics of durability of the bearing A (the left one) have a similar course as in the previous case, i.e. show maxima. Yet, in this case the maxima are significantly "moved" with respect one to the other, depending on the value of the axial force.

If the loads are applied closer to the right bearing, the characteristics of durability of the bearing $\mathrm{A}$, as well as those of the bearing $\mathrm{B}$, have various shapes, depending on the axial force. With high axial force (above $0.2 F_{c}$ ), the curves of durability of the bearing A show an increase up to a certain maximum, and for a lower axial force these curves monotonically drop down together with the values of preload increasing from 0 . At the same time, the curves of durability of the bearing B behave in an opposite way: the maximum appears with the axial force lower than $0.2 F_{c}$, whereas with the higher axial force the curves of durability of the bearing B drop down, although not very rapidly. 
The following observations result from the characteristics of $W_{T}$ :

- if the loads are applied to the shaft closer to the left bearing $\left(x_{L}=\right.$ $=0.4 L_{w}$ ), regardless of other factors (value of transversal and axial loads), the indicator of fatigue life $W_{T}$ decreases as the preload $Z_{c}$ increases. A relevant speed of the drop of $W_{T}$ indicator is quite similar in all the studied variations of transversal loads values. It can be also noticed that the lower the value of axial force affecting the bearing, the higher the speed of the drop;

- if the loads are applied in the middle of the distance between the bearings $\left(x_{L}=0.5 L_{w}\right)$, together with the increase of the preload from the zero value, the characteristics of the $W_{T}$ durability indicator run differently; in some cases they grow and in other cases they fall;

- if the loads are applied closer to the right bearing $\left(x_{L}=0.6 L_{w}\right)$, characteristics of durability indicator have various courses. The lines of durability indicator that represent the highest assumed axial force $\left(F_{x}=0.392 F_{c}\right)$, soar above the $W_{T}=1$. The lines for $F_{x}=0.196 F_{c}$ at a very short distance exceed the level $W_{T}=1$. The other lines related to a lower axial load have a clearly dropping character, which indicated a low acceptable preload in these cases.

In the case of the characteristics of the indicator $W_{M}$ it is easy to notice that all characteristics of $W_{M}$ factors are represented by the lines falling together with the increase of preload. They demonstrate great similarity in shape. It is known that the increase of the resistance of movement causes that more energy is used, more heat is emitted, and fluidity of movement required in delicate appliances (e.g. measuring ones) worsens. The falling character of the curves $W_{M}$ indicates that the values of preload must be restricted due to the increase of the movement resistances in the bearing system. Hence, a question arises: how high is the acceptable increase of movement resistances? There exists no clear answer to this question, because a lot depends on specificity of the application.

In the case of longitudinal stiffness of a bearing, it can be noticed that it increases together with the increase of preload. It is so in every case, with no exemption, which of course one can expected basing on the literature or on one's own intuition. The higher the preload, the higher the first derivative of the increase.

The increase in longitudinal stiffness of the bearing is a desired phenomenon (and the main objective when applying a preload), so from this point of view there is no limit for the value of preload. The restrictions can appear due to other phenomena: as a result of the increase in internal forces in bearings, which leads to the reduction of durability of bearings, in consequence of the increase of the moment of friction. 
Manuscript received by Editorial Board, October 22, 2015; final version, March 13, 2016.

\section{References}

[1] T.A. Haris. Rolling Bering Analysis. John Wiley \& Sons, London, 2006.

[2] H. Li and Y.C. Shin. Analysis of bearing configuration effects on high speed spindles using an integrated dynamic thermo-mechanical spindle model. International Journal of Machine Tools and Manufacture, 44(4):347-364, 2004.

[3] M.A. Alfares and A.A. Elsharkawy. Effects of axial preloading of angular contact ball bearings on the dynamics of a grinding machine spindle system. Journal of Materials Processing Technology, 136(1-3):48-59, 2003.

[4] SKF. Catalogue of bearings (Katalog tożysk tocznych), 1991 (in Polish).

[5] A. Raczyński. Obciążenie kulek w łożysku kulkowym skośnym w zależności od napięcia wstępnego (The ball load in the angular contact ball bearing in dependence on the preload). Tribologia (Tribology), (1):77-88, 2001 (in Polish).

[6] Y. Hwang and C. Lee. A review on the preload technology of the rolling bearing for the spindle of machine tools. International Journal of Precision Engineering and Manufacturing, 11(3):491-498, 2010.

[7] J. Kaczor and A. Raczynski. The effect of preload of angular contact ball bearings on durability of bearing system. Proceedings of the Institution of Mechanical Engineers, Part J: Journal of Engineering Tribology, 229(6):723-732, 2015.

[8] A. Raczyński. Obliczanie trwałości zmęczeniowej łożysk kulkowych zwykłych z uwzględnieniem luzu i ugięcia wału (The calculation method of deep groove ball bearings durability with regard to clearance and shaft). Zagadnienia Eksploatacji Maszyn (Scientific Problems of Machines Operation and Maintenance), 34(1):111-120, 1999 (in Polish).

[9] PREMA. Catalogue of bearings (Katalog tożysk tocznych), 2001 (in Polish).

[10] http://www.skf.com/group/products/bearings-units-housings/ball-bearings/angularcontact-ball-bearings/single-row-angular-contact-ball-bearings/singlerow/index.html?designation=7212BEP\&unit=metricUnit

\section{Wpływ napięcia wstępnego na pracę układu łożysk kulkowych skośnych}

Streszczenie

Optymalne wartości napięcia wstępnego można uzyskać ze sprawdzonych konstrukcji, a następnie zastosować w konstrukcjach podobnych. W przypadku nowych konstrukcji zaleca się obliczenie siły napięcia wstępnego i eksperymentalne sprawdzenie poprawności obliczeń. W praktyce może być potrzebne wprowadzenie korekt, ponieważ nie wszystkie rzeczywiste parametry pracy mogą być dokładnie znane. Wiarygodność obliczeń zależy przede wszystkim od tego, na ile założenia poczynione w stosunku do warunków temperaturowych podczas pracy i odkształceń sprężystych współpracujących elementów - przede wszystkim oprawy - zgodne są z warunkami rzeczywistymi. Celem niniejszej pracy jest określenie, jak wpływa napięcie wstępne na pracę układu łożysk kulkowych skośnych, z uwzględnieniem trwałości łożyskowania, momentu tarcia oraz sztywności łożyskowania. 